IN BRIEF

\section{Orlov appeal}

Almost 600 French physicists have signed a declaration in defence of Professor Yurii Orlov, founder of the unofficial Moscow 'Helsinki monitoring group'. This was announced this week at the close of the 'Orlov hearing', a mock trial staged at the Institute of Physics in London on the eve of the Belgrade review of the implementation of the Helsinki agreements.

Orlov was arrested on 10 February and is being held incommunicado in the Lefortovo prison in Moscow. He has not yet been formally charged, but it seems likely that when a charge is made it will be concerned with the activities of the monitoring group under the articles pertaining to anti-Soviet propaganda.

The case for the defence, presented in London by John Macdonald QC, analysed the 19 major documents on Soviet violations of the Helsinki agreements, maintaining that the content of the documents was true, and believed

RECENT reports that the United States is planning to build a radically new type of nuclear weapon, designed to kill people by releasing vast quantities of lethal neutrons while causing relatively little blast damage to buildings, may have been a bit misleading. Though details of the proposed weapons are shrouded in secrecy, a number of independent experts have told Nature that they are unlikely to differ significantly from the small tactical nuclear explosive already deployed in large numbers.

Funds to begin building the device, for use as a warhead on the Lance short range missile, are contained in budget proposals for the Energy Research and Development Administration (ERDA) which are now being considered by Congress. The first official public reference to the weapon came last March when General Alfred Starbird, Assistant ERDA Administrator for National Security, told a Congressional committee that it would be designed to "reduce the blast effect and get the kill radius you want through enhanced radiation".

All nuclear explosions give off energy in two forms: a blast and heat wave which causes physical destruction of buildings and other structures, and withering radiation in the form of gamma rays and fast neutrons (so-called prompt radiation) which can pass relatively easily through the atmosphere and penetrate solid material, including people. by the members of the group to be true. "Witnesses for the defence" included the mathematician Leonid Plyushch, Vladimir Bukovskii, and Marina Voikhanskaya, a phychiatrist who refused to cooperate with the Soviet misuse of psychiatry for political ends.

\section{Employment prospects}

The total number of scientists and engineers employed by private industry in the United States dropped by $5 \%$ in the first half of the $1970 \mathrm{~s}$, according to a study released last week by the National Science Foundation. The first major survey of scientific employment since 1970, the study also indicated that there has been a major shift in employment patterns, with manufacturing industry reporting a $13 \%$ drop and non-manufacturing industries indicating an $11 \%$ increase in the number of scientists and engineers they employed between 1970 and 1975. The figures refer to all scientists and engineers working in private industry.

In addition, radioactive debris from the explosive and from material sucked into the blast will later be deposited as potentially lethal fallout. It has long been known that the

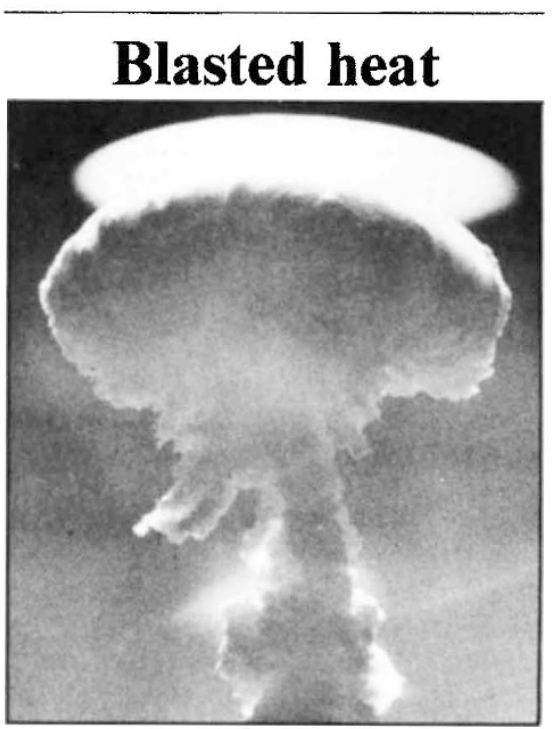

\section{BACKGROUNDER}

relative importance of these effects depends on a number of factors, including the size of the explosion, the design of the explosive, and the altitude at which it is detonated.

in general, the smaller the explosion, the greater is the relative output of prompt radiation. Design is particularly important: according to a book written two years ago by Theodore Taylor, a former weapons
Those directly employed in research and development departments declined particularly sharply, from 372,000 in 1970 , to 329,000 in 1975 - a $12 \%$ drop. Though the survey covered a period of economic recession, the decline in the number of scientists and engineers employed by private idustry was unexpectedly sharp. Recent indicators suggest, however, that the scientific job market may be picking up a little as the economy has improved.

\section{Cost-of-living for NSF}

Unmoved by protestations that academic science in the United States has been suffering from financial undernourishment, the House Appropriations Committee recently recommended that the National Science Foundation (NSF) should get no more than a costof-living increase for its support of basic research next year. The committee, which is the most powerful of the Congressional panels which handle NSF's budget, recommended that

designer, two explosives with the same explosive yield but with different designs could differ by at least a factor of 10 in their output of fast neutrons. In particular, thermonuclear fusion reactions, which take place in hydrogen bombs, are particularly efficient producers of fast neutrons.

Until recently, the chief goal of weapons designers was to produce high-yield explosives which would destroy targets through blast and heat. These are usually fissionfusion-fission devices in which a fission bomb is used to trigger a fusion reaction which in turn sets off a fission reaction in a blanket of uranium surrounding the device. More recently, design has shifted more toward so-called 'mini-nukes', weapons with small explosive yields which could be used with very accurate missiles to knock out small targets. Again, heat and blast would constitute the chief destructive force of the weapon.

The proposed new 'enhanced radiation' weapon is believed to be a modified mini-nuke, possibly a small fusion device, triggered by a low-yield fission explosion, without the surrounding blanket of uranium. The important point to note is that although the weapon is designed to give out relatively large amounts of neutrons, the heat and blast effects would still be substantial-according to some experts they would probably still account for the largest fraction of the weapon's energy output. 